\title{
A post menopausal female with empty sella syndrome
}

\author{
Vithiya $\mathrm{R}^{1}$, Suganthan $\mathrm{N}^{2}$, Selvaratnam $\mathrm{G}^{3}$, Kumanan $\mathrm{T}^{2}$
}

\section{Summary}

Empty sella syndrome is an incidental anatomical finding which can occasionally present as hypopituitarism. Here we report a post-menopausal female with emptysella syndrome and anterior pituitary hormone deficiency. She is a 69 year-old mother of four children presented with progressively worsening lethargy and constipation. Her last pregnancy at 24 years was complicated with post-partum haemorrhage. She had breastfed her last child for an year. She attained menopause at the age of 45. Investigations revealed normocytic anemia, and hyponatremia. Hormonal profile showed a normal TSH level $(2.09 \mathrm{mu} / \mathrm{l})$ and low free $\mathrm{T} 4(<0.07 \mathrm{ng} / \mathrm{dl})$ suggestive of secondary hypothyroidism. She also had low level of 9am cortisol, and inappropriately low FSH and LH levels. Non-contrast computerized tomography of the brain revealed cerebrospinal fluid(CSF) within sella-turcica, suggestive of empty-sella syndrome. She was treated with replacement doses of hydrocortisone and thyroxine and with that her symptoms improved.

\section{Background}

Empty sella syndrome is a rare clinical condition in which the sella turcica or pituitary fossa is filled with cerebrospinal fluid resulting in compression of pituitary gland. It can be an incidental finding in autopsy[1] or radiological evaluation [2]. Varying degree of hypopituitarism is observed in patients with empty sella syndrome and it can be quite severe [3]. Here we present a case of empty-sella syndrome and hypopituitarism in a post menopausal female.

\section{Case presentation}

A 69 year old mother of four children presented with a history of progressively worsening lethargy and exertional tiredness for last 2 years duration. She also had constipation and cold intolerance. There is no history of vision problems galactorrhoea, polyuria or postural giddiness. She is a known patient with migraine, but did not have recent worsening of headache frequency and was not on any prophylaxis. She attained menopause at the age of 45 years. Her last pregnancy at the age of 24 years was complicated with postpartum hemorrhage, and she was transfused blood. She had breastfed her last child for 1 year. There is no past history of meningo encephalitis.

On examination she was pale and found to have dry skin. She had blepharoptosis and bilateral non pitting ankle oedema. Her pulse rate was 60 beats/min, and blood pressure was $130 / 80 \mathrm{mmHg}$ with no postural drop. Cranial nerve examination including optic fundi was normal and no visual field defects noted. There was no goiter. BMI was 23 .

Investigations revealed Normocytic anemia with a $\mathrm{Hb}$ level of $10 \mathrm{~g} / \mathrm{dl}$, and mean corpuscular volume of $92 \mathrm{fl}$. Plasma Sodium was $134 \mathrm{mmol} / \mathrm{l}$, Potassium $4.1 \mathrm{mmol} / \mathrm{l}$, and Calcium $2.29 \mathrm{mmol} / \mathrm{l}$. Thyroid stimulating hormone(TSH) was within normal range $(2.09 \mathrm{mu} / \mathrm{l})$ but free T4 was low $(<0.07 \mathrm{ng} / \mathrm{dl})$. Her hormonal profile showed reduced level of 9 am cortisol of $44.5 \mathrm{nmol} / \mathrm{l}$ (171-536nmol/l) and inappropriately low Follicle stimulating hormone(FSH) and Luteinizing hormone (LH) levels for her age. FSH was $6.79 \mathrm{mIU} / \mathrm{ml}$ (Postmenopausal 30.6-106.3 mIU/mL), LH -2.08 (Postmenopausal 15.0-62.0 mIU/mL ),and serum prolactin $142 \mathrm{mIU} / \mathrm{l}(40-530 \mathrm{mIU} / \mathrm{l})$. Serum and urine osmolarity were normal. Non-contrast computerised tomography of the brain revealed CSF within sella-turcica, suggestive of empty-sella syndrome. Electrocardiogram and Trans thoracic 2 dimensional echocardiogram were normal.

A diagnosis of hypopituitarism was made and she was commenced on hydrocortisone $10 \mathrm{mg}$ mane, $5 \mathrm{mg}$ noon and $5 \mathrm{mg}$ nocte followed by thyroxine $25 \mathrm{micrograms}$ daily, which was increased to 50micrograms in further two weeks. Her symptoms improved on review after 6 weeks from the initiation of treatment. Thyroid function was monitored at regular intervals with free T4 levels and thyroxine dose was adjusted accordingly, and currently she is in euthyroid status with thyroxin 125 micrograms

${ }^{1}$ Registrar in Medicine, Professorial Medical unit, Teaching Hospital Jaffna, ${ }^{2}$ Consultant Physician and senior Lecturer, Professorial Medical unit, Teaching Hospital Jaffna, ${ }^{3}$ Consultant Chest Physician and Senior Lecturer, Professorial Medical unit, Teaching Hospital Jaffna 
daily. Glucocorticoid replacement was assessed clinically and patient was educated regarding dose adjustment for intercurrent illness.

\section{Discussion}

Our patient who presented with clinical features of hypothyroidism was diagnosed to have secondary hypothyroidism. Menopause at the age of 45 years and inappropriately low FSH and LH levels coupled with the low serum cortisol prompted us to make the diagnosis of anterior pituitary insufficiency. There were no clinical features or biochemical evidence of posterior pituitary dysfunction. Most of the cases of adult hypopituitarism in empty sella syndrome is due to primary pituitary dysfunction except for a few cases in which hypothalamic dysfunction has been demonstrated [4]. However we could not assess the hypothalamic function in our patient due to limited resources.

Empty sella syndrome can be either primary or secondary. Inherited abnormalities of the sella diaphragm and or increased intracranial pressure resulting in herniation of arachnoid membrane into the pituitary fossa are classified as primary empty sella syndrome [5]. Empty sellar syndrome resulting from physiological volumetric changes in pregnancy is also classified as primary empty sella syndrome,whereas cases following volumetric changes in pituitary fossa due to tumor, infarction, hemorrhage, infection, radiotherapy or auto immunity are classified as secondary empty sella syndrome[6]. In our patient multiparity, and gender support the diagnosis of primary empty sellar syndrome. Although she had a history of post partum hemorrhage, establishment of breast feeding, and regular menstruation until age of 45 years makes the diagnosis of Sheehan syndrome less likely as the cause for hypopituitarism or secondary empty sella syndrome.

Interestingly our patient had a history of migraine, and it is known to be associated with empty sella along with hypertension and obesity [7].

Although measurement of serum TSH is recommended as the primary screening test for thyroid dysfunction, it can miss the rare cases of secondary hypothyroidism. In our patient TSH was within normal range. In central hypothyroidism TSH values are usually low or normal but it can be slightly elevated in $11 \%$ of the cases. It is partly because of the immunoactive but biologically inactive forms of TSH secreted by the pituitary gland [8].

Performing free T4 levels along with TSH when there is a high degree of clinical suspicion of hypothyroidism will increase diagnostic yield and eliminate diagnostic confusion. In patients with pituitary disease, TSH monitoring is unhelpful and thyroxine replacement should be aimed towards clinical improvement along with normalisation of free thyroxine level [9].

\section{Take home messages or learning point}

Patients with hypopituitarism exhibit a slow and progressive loss of pituitary function with vague symptoms. Empty sella syndrome is a rare cause for hypopituitarism. A Normal TSH level does not imply euthyroid status. Performing free T4 levels along with TSH when there is a high degree of clinical suspicion of hypothyroidism will increase the diagnostic yield of secondary hypothyroidism.

\section{Abbreviations}

$\mathrm{CSF}=$ Cerebro spinal fluid, $\mathrm{TSH}=$ thyroid stimulating hormone, $\mathrm{FSH}=$ follicle stimulating hormone, $\mathrm{LH}=$ luteinizing hormone

\section{References}

1. Busch W, Morphology of sella turcica and its re- lation to the pituitary gland. Virchows Arch 1951, 320:437- 458. Available from: https://www.ncbi.nlm.nih.gov/pubmed/14942993

2. Debnath J, Ravikumar R, Sharma V, et al. "Empty sella" on routine MRI studies: An incidental finding or otherwise? Med journal, Armed Forces India. 2016;72(1):33-37. Available from:doi:10.1016/j.mjafi.2015.11.012.

3. Durodoye OM, Mendlovic DB, Brenner RS, Morrow JS. Endocrine disturbances in empty sella syndrome: case reports and review of literature. Endocr Pract. 2005;11(2):120-124. Available from:doi:10.4158/EP.11.2.120.

4. Komada H, Yamamoto M, Okubo S, et al. A case of hypothalamic panhypopituitarism with empty sella syndrome: case report and review of the literature. Endocr J. 2009;56(4):585-589. Available from:doi:10.1507/endocrj.K08E-214.

5. Jordan RM, Kendall JW, Kerber CW. The primary empty sella syndrome: analysis of the clinical characteristic, radiographic features, pituitary function and cerebral fluid adeno-hypophysial concentrations. Am J Med 1977;62:569580. Available from: https://www.ncbi.nlm.nih.gov/ pubmed/851132

6. Marinis L De, Bonadonna S, Bianchi A, Maira G, Giustina A. Primary Empty Sella.J Clin Endocrinol Metab. 2005;90(9):54715477. Available from: doi:10.1210/jc.2005-0288.

7. Degli U E C, Teodori V, Trasforini G, et al. The empty sella syndrome. Clinical, radiological and endocrinologic analysis in 20 cases; Minerva Endocrinol, 1989;14 (1):1-18

8. Miller KJ, Parsons TD, Whybrow PC, Van Herle K, Rasgon N, Van Herle A, et al. Verbal memory retrieval deficits associated with untreated hypothyroidism. J Neuropsychiatry Clin Neurosci. 2007;19:132-6. Available from:doi:10.1176/ jnp.2007.19.2.132.

9. Franklyn JA. Diagnosis and treatment of thyrotropin deficiency. In:Lamberts $\mathrm{S}$, ed. The diagnosis and treatment of pituitary insufficiency. Bristol:BioScientifica, 1997:99-111. 